\title{
LESÕES ESPORTIVAS: UM ESTUDO COM ATLETAS DO BASQUETEBOL BAURUENSE*
}

\author{
GRAD. BRUNO ESTEVAN SIQUEIRA DARIO \\ Bacharel em educação física - FIB \\ Personal trainner \\ E-mail: bruno.personal@msn.com
}

\author{
GRAD. GUSTAVO BARQUILHA \\ Mestrando em ciências do movimento humano - Unicsul - Bolsista da Fapesp \\ E-mail: gustavo_barquilha@hotmail.com \\ MS. REINALDO MONTEIRO MARQUES \\ Doutorando em biologia oral - USC \\ Coordenador do curso de Pós-Graduação em Fisioterapia Esportiva - FIB \\ E-mail: reinaldomm@uol.com.br
}

\begin{abstract}
RESUMO
Este estudo teve como objetivo identificar as principais lesões no basquetebol e suas incidências. Participaram do estudo vinte jogadores de basquetebol do sexo masculino com idade variando entre 13 e 15 anos. 0 instrumento utilizado foi o questionário e seus resultados mostraram que, dos atletas participantes do estudo, todos relataram algum tipo de lesão. Foram identificadas 26 lesões, sendo 13 nos membros inferiores (50\%) e 13 nos membros superiores (50\%). No joelho, as lesões mais frequentes foram a tendinite patelar - sete casos (53,85\%). Nos membros superiores, destacaram-se as entorses nos dedos das mãos - cinco casos (38,46\%). Com este estudo, percebemos a necessidade de se desenvolver um trabalho preventivo no intuito de diminuir a incidência dessas lesões.
\end{abstract}

PALAVRAS-CHAVE: Basquetebol; lesões esportivas; avaliação no basquete.

* O presente trabalho não contou com apoio financeiro de nenhuma natureza para sua realização. Não houve conflitos de interesses para realização do presente estudo. 
É cada vez maior o número de crianças e adolescentes que buscam alguma pratica esportiva. Nesse grupo, essa prática pode trazer benefícios, como a melhora na composição corporal (BORTONI; BoJIIIAN, 2007), aumento da densidade e do diâmetro ósseo (BORTONI; BoJIKIAN, 2007; STRONG, 2005), aptidão física (MARQUES; GonZÁlEs-BADILlo, 2005), entre outros. Porém, cada esporte tem suas características próprias de espaço, tempo, dinâmica e exigências físicas, e podem trazer também modificações negativas, como, por exemplo, algum tipo de lesão (SCHAFLE et al., 1992). Cohen e Abdalla (2003) definem lesão como um dano causado por traumatismo físico sofrido pelos tecidos do corpo. Nesse sentido, Gantus e Assumpção (2002) citam que a prática esportiva eleva o risco de ocorrência de lesões mesmo em atletas jovens. Os atletas estão sujeitos a sofrer lesões seja em fase de treinamento, seja em competição, sendo que essas lesões estão diretamente relacionadas a fatores predisponentes intrínsecos e extrínsecos, e à ausência de um programa preventivo. A incidência e a severidade das lesões estão diretamente relacionadas aos seguintes fatores: pessoais, modalidades esportivas praticadas e ambientais, característicos de cada uma delas (Cohen; AbDalla, 2003).

Um exemplo que podemos seguir é a prática do basquete, esporte coletivo em que há contato físico com o adversário, o que poderá acarretar diferentes lesões, considerando que os atletas mantêm um contato físico constante. Além delas, podem-se também considerar as lesões decorrentes dos constantes deslocamentos, saltos e movimentos bruscos (HOFFMAN et al., 2000).

O basquetebol é um esporte que exige contato entre os jogadores tanto na defesa quanto no ataque. Além disso, o basquetebol baseia-se principalmente em três capacidades físicas condicionantes: força, resistência e velocidade (McINNES et al., 1995). Segundo Cohen e Abdalla, (2003), os movimentos básicos do basquete são: o arremesso, o drible, o passe, a bandeja, o rebote e a posição de defesa.

Esses movimentos estão associados a princípios físicos, como força de reação do solo, força da gravidade, aceleração, momento, força de parada, deslocamento do centro de massa, atrito e princípios de alavanca. É um jogo com constantes mudanças de direção e contato físico, e permite entender o aparecimento de determinadas patologias. $\bigcirc$ atleta fica exposto às lesões traumáticas e por sobrecarga (Cohen; Abdalla, 2003).

Nesse esporte, a maior carga de trabalho ocorre nos membros inferiores, o que pode provocar um grande número de lesões, decorrentes dos deslocamentos, 
mudanças bruscas de direção e saltos. Porém, segundo Cohen et al. (1997), as lesões podem afetar qualquer parte do corpo, observando-se uma vulnerabilidade específica segundo o tipo de movimento corporal exigido para a atividade esportiva que é praticada. Observando todos os riscos inerentes da prática de uma atividade esportiva, em especial no basquete, o objetivo deste trabalho foi identificar as principais lesões nos praticantes de basquetebol da cidade de Bauru, das categorias mirins e infantis do sexo masculino no período de treinamento da Liga de Basquete do Centro Oeste Paulista, do biênio 2007/2008.

\section{METODOLOGIA}

\section{PARTICIPANTES}

Participaram do estudo 20 atletas, com idade média de 13,8 \pm 0,89 anos, peso de 64,0 I \pm 1 I,49 kg e altura I,76 \pm 0, I I metros, praticantes de basquetebol na cidade de Bauru, todos do gênero masculino. Esses atletas treinavam durante 90 minutos em média, 4 vezes por semana. Os participantes foram confirmados no estudo após manifestação por escrito de termo de consentimento livre e esclarecido, aprovado pelo Comitê de Ética e Pesquisa das Faculdades Integradas de Bauru (Protocolo n. 0006/08PSH).

\section{APLICAÇÃO DE QUESTIONÁRIO}

Por meio de um questionário com perguntas abertas e fechadas sobre a ocorrência de lesões em atletas do sexo masculino praticantes do basquetebol (Anexo l), foi aplicada uma metodologia qualitativa e quantitativa, a fim de se obterem dados sobre a frequência das lesões dessa modalidade esportiva no grupo. O questionário foi aplicado sempre pelo mesmo avaliador. Como critério de inclusão, os atletas teriam de ter entre 13 e 15 anos de idade. Além disso, as lesões apresentadas pelos atletas foram consideradas válidas apenas quando diagnosticadas por médicos ou fisioterapeutas.

\section{RESULTADOS}

Na tabela I são relacionados todos os atletas de cada posição, sendo 8 pivôs, 8 laterais e 4 armadores, totalizando 20 atletas. Esses atletas fazem parte das categorias mirim e infantil da equipe de Bauru de basquetebol. 
Tabela I: Número de indivíduos por posições

\begin{tabular}{lll}
\hline Posições & Número de indivíduos & Porcentagem (\%) \\
\hline Pivô & 8 & 40 \\
Lateral & 8 & 40 \\
Armador & 4 & 20 \\
\hline Total & 20 & 100 \\
\hline
\end{tabular}

$\mathrm{Na}$ tabela 2, observamos que tanto em membros superiores quanto em inferiores o número de lesões é de 13. Esse resultado demonstra um equilíbrio entre os segmentos.

Tabela 2: Índice de lesões por segmento

\begin{tabular}{lll}
\hline Segmento & Valor absoluto & Porcentagem (\%) \\
\hline Membros superiores & 13 & 50 \\
\hline Membros inferiores & 13 & 50 \\
\hline Total & 26 & 100 \\
\hline
\end{tabular}

Na tabela 3, é demonstrado o índice de lesões em membros inferiores. A lesão mais comum foi a tendinite no joelho, com 7 lesões, seguida pela entorse de tornozelo, com 2 lesões.

Tabela 3: Índice de lesões em membros inferiores

\begin{tabular}{lll}
\hline Membros inferiores & Valor absoluto & Porcentagem (\%) \\
\hline Tendinopatia do tendão quadricipital do & 7 & 53,85 \\
joelho & 2 & 15,39 \\
Entorse de tornozelo & 1 & 7,69 \\
Fratura de tornozelo & 1 & 7,69 \\
Entorse do ligamento colateral do joelho & 1 & 7,69 \\
Estiramento do músculo adutor & 1 & 100 \\
\hline Total & 13 & \\
\hline
\end{tabular}

Na tabela 4, observamos que a lesão mais comum em membros superiores foi a entorse do dedo da mão, com 5 ocorrências, em seguida, a fratura de punho, com 3 ocorrências. 
Tabela 4: Índice de lesões em membros superiores

\begin{tabular}{lll}
\hline Membros superiores & Valor absoluto & Porcentagem (\%) \\
\hline Entorse de dedo da mão & 5 & 38,46 \\
\hline Fratura de punho & 3 & 23,09 \\
\hline Fratura de braço & 2 & 15,38 \\
\hline Fratura dedo da mão & 2 & 15,38 \\
\hline Tendinopatia de punho & 1 & 7,69 \\
\hline Total & 13 & 100 \\
\hline
\end{tabular}

Na tabela 5, observamos a relação de lesões por posição. A posição na qual houve o maior número de lesões foi a de pivô, com 12 lesões no total; seguida pela dos laterais, com 8 lesões, e pela dos armadores, com 6 lesões.

Tabela 5: Número de lesões por posições

\begin{tabular}{lll}
\hline Posições & Valores absolutos das lesões & Porcentagem (\%) \\
\hline Pivôs & 12 & 46,15 \\
\hline Armadores & 6 & 23,08 \\
\hline Laterais & 8 & 30,77 \\
\hline Total & 26 & 100 \\
\hline
\end{tabular}

\section{DISCUSSÃO}

Indivíduos cuja faixa etária está entre 13 e 17 anos são caracterizados pela rápida aquisição de conteúdo mineral ósseo. Nessa fase, ocorre o pico de massa óssea, que é quando o processo de formação sobrepuja o de reabsorção óssea (PHILLIP; LAZAR, 2003; Silva et al., 2004; Pettersson et al., 2000). Astrand (I 992) complementa que indivíduos dessa faixa etária, tanto no aspecto funcional quanto no aspecto estrutural, não são semelhantes aos adultos. Nesse aspecto, Georgopoulos et al. ( 1999) citam que a atividade física mal estruturada pode trazer efeitos maléficos aos indivíduos dessa idade, como atenuação do crescimento físico, risco de lesões, entre outros. A correta estruturação do treinamento é de fundamental importância para que não ocorram prejuízos à saúde dos indivíduos dessa população, principalmente os que praticam uma modalidade desportiva. Além disso, também devem ser levados em consideração outros aspectos além do treinamento, como, por exemplo, os aspectos nutricionais desses atletas, já que a nutrição está justamente relacionada 
com a proliferação da cartilagem de crescimento e o alongamento linear dos ossos (Rogol et al., 2000). Apesar de todas as precauções que devem ser tomadas quanto à prática esportiva competitiva realizada por crianças e adolescentes, pouco se conhece dos efeitos que tais práticas podem ter sobre esses indivíduos.

O presente estudo mostrou que, dos 20 atletas que responderam ao questionário, 20 (100\%) declararam algum tipo de lesão. Foram relatadas 26 lesões, sendo 13 (50\%) em membros superiores (MMSS) e 13 (50\%) em membros inferiores (MMII), sendo os mesmos resultados relatados por De Rose et al. (2006). A lesão mais frequente foi a tendinite no joelho, com 7 casos (53,85\%). Foram quantificados na articulação do joelho 9 casos (69,23\%), também identificados nos estudos citados por Menezes (2003) com atletas da Liga Espanhola e da NBA, e por Meeuwisse et al. (2003) no Campeonato Universitário Canadense. No Brasil, Moreira et al. (2003) constataram casos de tendinite patelar em atletas da Seleção Brasileira, sendo que os pivôs foram os mais lesionados.

Nos membros superiores, percebemos a maior ocorrência de entorses nos dedos das mãos, com 5 casos (38, 46\%), e de fratura de punho, com 3 casos (23,09\%), também relatados por Cohen e Abdalla (2003), com 75\% do índice de lesões. Nessas regiões, o número de lesões é significativamente menor, mas elas também podem afastar os atletas de suas atividades por longos períodos, prejudicando seu desempenho e o da equipe. Um dado interessante aponta que, das 26 lesões encontradas, 12 (46, 15\%) são nos pivôs. Esse resultado pode ser devido ao fato de esses atletas geralmente serem mais altos, sendo submetidos a treinamentos mais específicos e ficando restritos ao garrafão. Em razão disso, os pivôs geralmente ficam de fora dos treinamentos a que laterais e armadores são submetidos. Starkey (200 I), em uma análise de lesões de 12 diferentes esportes, constatou que o basquetebol, juntamente com hóquei no gelo, handebol e esqui, é uma das modalidades esportivas com maior incidência de lesões no joelho. Nos homens, elas ocorrem em 10\% dos casos e nas mulheres em 13\%.

Observando jogos de basquetebol de diferentes idades, em ambos os sexos, Silva (2002) constatou que as lesões de tornozelo foram as mais frequentes, sendo que em $45 \%$ dos casos elas ocorreram na fase de aterrissagem após arremessos e rebotes. Nesse estudo, o autor também constatou um grande número de lesões na panturrilha e no joelho. Silva (2002) também notou que o joelho (21\%), as mãos e os dedos (17\%), a perna/coxa e os tornozelos ( $14 \%$ cada) foram os locais mais lesionados em 66 atletas de cinco equipes femininas do estado de São Paulo. Das atletas analisadas, com idades entre 18 e 37 anos, 47 (7 I\%) apontaram pelo menos uma lesão. A lesão mais comum nesse grupo foi entorse de tornozelo (33\%). 
Gantus e Assumpção (2002) entrevistaram 59 atletas de sete equipes masculinas adultas do estado de São Paulo, com idades variando entre 18 e 39 anos, e concluíram que as entorses de tornozelo foram as mais frequentes, seguidas por tendinites patelares, ferimentos nos supercílios e lábios, e contusão na coxa. Nos armadores, a região mais acometida foi o tornozelo; nos laterais, a face; e nos pivôs, a face, as mãos e os dedos.

Dentre as lesões nos membros superiores no basquetebol, as lesões articulares nas mãos e nos dedos (por ocasião de traumas diretos com a bola) são as mais frequentes, sendo cerca de $75 \%$ os casos de luxação e $96 \%$ os casos de fraturas constatados em diversos estudos (COHEN e ABDAlLA, 2003). Esses mesmos autores ainda afirmam que os membros inferiores foram os mais lesionados na Liga Espanhola de Basquetebol (46\%) e na NBA (57\%). A maior incidência dessas lesões ocorreu no tornozelo (entorse), seguido por lesões no joelho (entorse e tendinite patelar). As luxações nos dedos das mãos também apareceram com muita frequência na amostra estudada.

Moreira et al. (2003), em estudo com a Seleção Brasileira de Basquetebol masculino na fase preparatória para o Campeonato Mundial de 2002, concluíram que a maior incidência de lesões ocorreu nos membros inferiores, com destaque para entorse no tornozelo. As contusões nas mãos, estiramentos na região adutora e perna, lombalgia e tendinite patelar, também foram identificadas. Os pivôs foram os atletas que mais relataram queixas, seguidos dos laterais e armadores.

Vale ressaltar que o presente estudo foi realizado com indivíduos de 13 a I 5 anos de idade. Até o momento, não conseguimos identificar na literatura outros estudos com indivíduos dessa faixa etária jogadores de basquete, sendo que os altos índices de lesões encontrados nesses atletas vão ao encontro a resultados encontrados em indivíduos adultos. Safran et al. (2002) afirmam que a busca pela evidência e pelo sucesso expõe os atletas a uma condição de serem submetidos a um esforço físico e psicológico muito próximo dos limites fisiológicos, fazendo com que o número de lesões seja muito alto. Esse processo pode também ser um fator preponderante para o alto índice de lesões mesmo em crianças.

\section{CONCLUSÃO}

Foi observado no presente estudo um alto índice de lesão em atletas da categoria de base do basquete bauruense. Esse alto índice pode ser decorrente de o basquete ser um esporte de muito contato físico. Talvez um trabalho visando à recuperação do equilíbrio e da estabilidade, além do uso de gestos esportivos, seja 
interessante na prevenção dessas lesões (GANTus e AssumPção, 2002) , podendo ser aplicado desde a iniciação esportiva.

\section{Sports injuries: a study with basketball athletes of Bauru city}

ABSTRACT: This study aimed to identify key injuries in basketball and its impact. In the present study the participants were 20 male basketball players aged between 13 and 15 years. The instrument used was the questionnaire and its results showed that the athletes participating in the study, all reported some type of injury. 26 lesions were identified, of which 13 in the lower limbs (50\%), 13 upper limbs (50\%). With the knee injuries were the most frequent patellar tendinitis 7 cases (53.85\%). In the upper limb are highlighted sprains of fingers with 5 cases (38.46). This study realized the need to develop a preventive work in order to reduce the incidence of these injuries.

KEY WORDS: Basketball; sports injuries; assessment in basketball.

\section{Lesiones deportivas: un estudio con atletas de baloncesto de la ciudad de Bauru}

RESUMEN: Este estudio tuvo como objetivo identificar cuales son las principales lesiones que afectan a los jugadores de baloncesto y mostrar su incidencia. Participaron del estudio 20 baloncestistas, todos hombres de edades comprendidas entre 13 y 15 años. El instrumento utilizado en este trabajo fue un cuestionario. Los resultados demostraron que todos los participantes tuvieram algún tipo de lesión causada por el baloncesto. Fueron identificadas 26 lesiones de las cuales 13 ocurrieron en los miembros inferiores (50\%) y 13 en los miembros superiores (50\%). La lesión más frecuente en la rodilla fue la tendinitis patelar, con 7 casos (53,85\%). En los miembros superiores destacaronse los esguinces en los dedos de las manos, con 5 casos (38,46\%). Con este estudio fue posible percibir la necesidad del desarrollo de un trabajo preservativo buscando a la disminución de la incidencia de estas lesiones.

PALABRAS CLAVES: Baloncesto; lesiones deportivas; la evaluación en baloncesto.

\section{REFERÊNCIAS}

ASTRAND, P. O. Crianças e adolescentes: desempenho, mensurações, educação. Revista Brasileira de Ciência e Movimento, Brasília, v. 6, n. 2, p. 59-68, 1992.

BORTONI, W. L.; BOJIKIAN, L. P. Crescimento e aptidão física em escolares do sexo masculino, participantes de programa de iniciação esportiva. Brazilian Journal of Biomotricity, Rio de Janeiro, v. I, n. 4, p. I|4-122, 2007.

COHEN, M.; ABDALLA, R. J. Lesões nos esportes - Diagnóstico, prevenção e tratamento. São Paulo: Revinter, 2003. 
COHEN, M.; ABDALLA, R. J.; EJNISMAN, B.; AMARO, J. T. Lesões ortopédicas no futebol. Revista Brasileira de Ortopedia, São Paulo, v. 32, n. 12, p. 940-944, 1997.

DE ROSE, G.; TRADIELLO, F. F; DE ROSE J. R. Lesões esportivas: um estudo com atletas do basquetebol brasileiro. Lecturas, Educacíon Física Y Deportes, Buenos Aires, ano 10, n. 94, mar. 2006. Disponível em: <http://www.efdeportes.com>. Acesso em: 3 mar. 2008.

GANTUS, M. C.; ASSUMPÇÃO, J. D. A. Epidemiologia das lesões do sistema locomotor em atletas de basquetebol. Acta Fisiátrica, São Paulo, v. 9, n. 2, p. 77-84, 2002.

GEORGOPOULOS, N. et al. Growth and pubertal development in elite female rhythmic gymnasts. Journal of Clinical Endocrinology \& Metabolism, Washington, v. 84, n. 12, p. 52530, 1999.

HOFFMAN, J. R.; EPSTEIN, S.; EIBINDER, M.; WEINSTEIN, Y. The comparision betweem the Wingate Anaerobic Power Test to both vertical jump and Line Drill tests in basketeball players. Journal of Strength and Conditioning Research, Connecticut, v. 4, n. 3, p. 26I-264, 2000.

MARQUES, M. A. C.; GONZÁLEZ-BADILLO, J. J. O efeito do treino de força sobre o salto vertical em jogadores de basquetebol de 10-13 anos de idade. Revista Brasileira de Ciência e Movimento, Brasília, v. 13, n. 2, p. 93-100, 2005.

MEEUWISSE, W. H.; SELLMER, R.; HAGEL, B. E. Rates and risks of injury during intercollegiate basketball. American Journal of Sport Medicine, Chicago, v. 31, n. 3, p. 379-385, 2003.

MENEZES, P. J. M. Lesiones em el baloncesto: epidemiologia, patologia, terapêutica y rehabilitación de lãs lesiones. Lecturas en Educación Física Y Deportes, v. 9, n. 62, 2003. Disponível em: <http://www.efdeportes.com>. Acesso em: 3 mar. 2008.

MCINNES S. E.; CARLSON J. S.; JONES C. J.; MCKENNA M. J. The physiological load on basketball players during competition. International Journal of Sports Sciense, Wolverhampton, v. 13, n. 5, p. 387-397, 1995.

MOREIRA, P.; GENTIL, D.; OLIVEIRA, C. Prevalência de lesões na temporada 2002 da Seleção Brasileira Masculina de Basquete. Revista Brasileira de Medicina do Esporte, São Paulo, v. 9 , n. 5, p. 258-262, 2003.

PETTERSSON, U.; NORDSTRÖM, P.; ALFREDSON, H.; HENRIKSSON-LARSÉN, K.; LORENTZON, R. Effect of high impact activity on bone mass and size in adolescent females: a comparative study between two different types of sports. Calcified Tissue International, London, v. 67, n. 3, p. 7-14, 2000.

PHILLIP, M.; LAZAR, L. The regulatory effect of hormones and growth factors on the pubertal growth sport. Endocrinology, v. 3, n. 6, p. 65-69, 2003. 
ROGOL, A. D.; CLARK, P. A.; ROEMMICH, J. N. Growth and pubertal development in children and adolescents: effects of diet and physical activity. American Journal of Clinical Nutrition, California, v. 2, n. 2, p. 21-28, 2000.

SAFRAN, M. R., MCKEAG, D. B., VAN CAMP, S. P. Manual de medicina esportiva. São Paulo: Manole, 2002.

SCHAFLE, M. D.; REQUA, R. K.; PUTTON, W. L. Injuries in the National Amateur Volleyball Tournament. American Journal of Sports Medicine, Chicago, v. 18, n. 6, p. 624-63 I, 1992.

SILVA, A. S. Incidência de lesões musculoesqueléticas em atletas de elite do basquetebol feminino. Dissertação (Mestrado em Reabilitação). - Escola Paulista de Medicina, São Paulo, 2002.

SILVA, C. C.; GOLDBERG, T. B. L.; TEIXEIRA, A. S.; DALMAS, J. C. Mineralização óssea em adolescentes do sexo masculino: anos críticos para a aquisição da massa óssea. Jornal de Pediatria, Porto Alegre, v. 80, n. 6, p. 46I-467, 2004.

STARKEY, C. Avaliação de lesões ortopédicas e esportivas. São Paulo: Manole, 200 I .

STRONG, W. B. et al. Evidence based physical activity for school-age youth. The Journal of Pediatrics, Cincinnati, v. I46, n. 6, p. 732- 737, 2005.

Recebido: 29 abr. 2009 Aprovado: 20 out. 2009

Endereço para correspondência Gustavo Barquilha Joel Instituto de Ciências da Atividade Física e Esporte Universidade Cruzeiro do Sul R. Galvão Bueno, 868 - 13, Bloco B Liberdade, São Paulo-SP CEP 0I 506-000 
ANEXO I: QUESTIONÁRIO APLICADO À OCORRÊNCIA DE LESÕES EM ATLETAS DO SEXO MASCULINO DO BASQUETE BAURUENSE

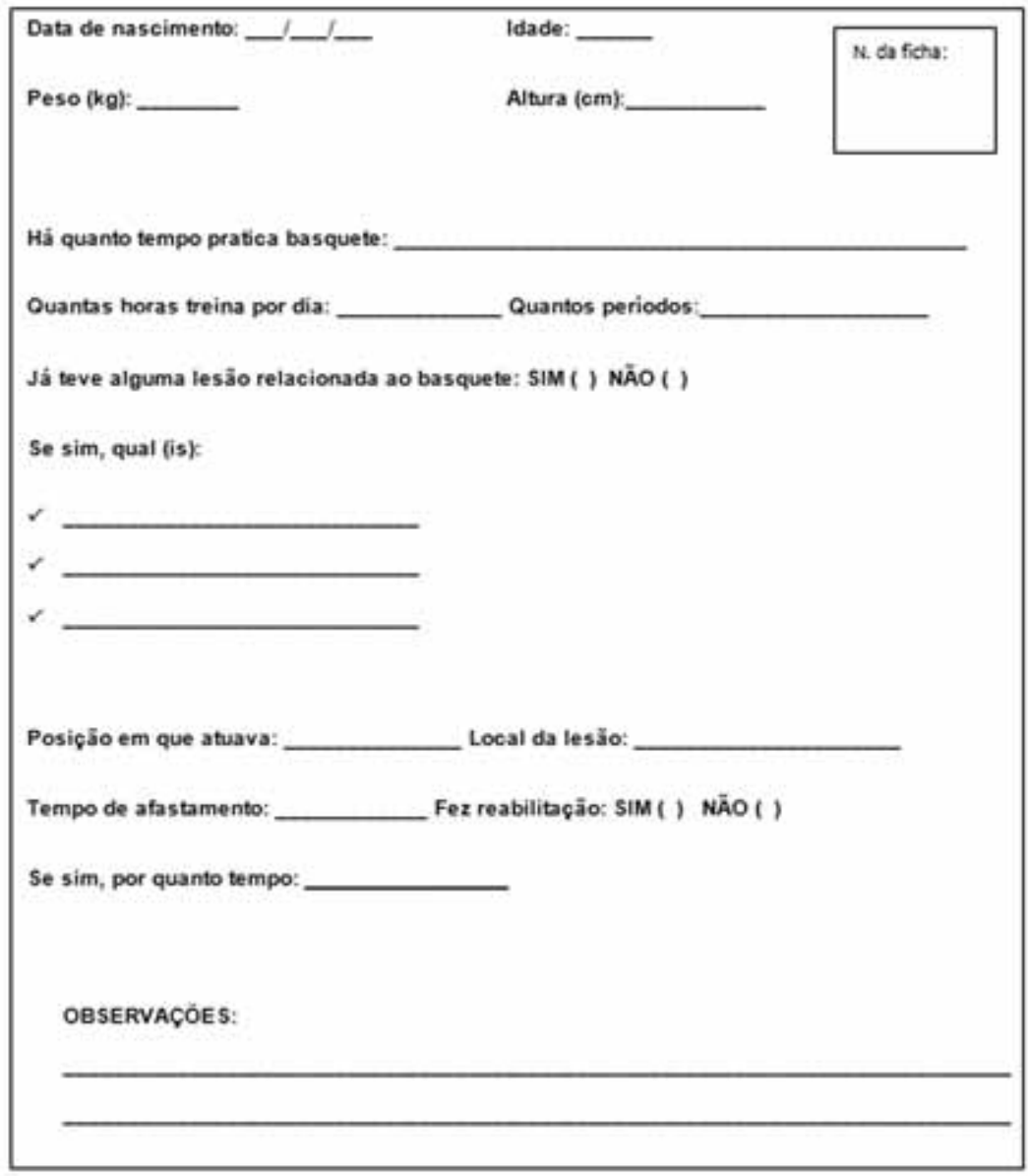

